\title{
Concentrate for Solution for Fish Treatment Dosage Form
}

National Cancer Institute

\section{Source}

National Cancer Institute. Concentrate for Solution for Fish Treatment Dosage Form.

NCl Thesaurus. Code C149399.

Liquid preparation intended to be diluted in the specified liquid to obtain a solution for fish treatment by immersion. 